УДК 364.4-053.2

О. Г. Седых

Байкальский государственный университет, г. Иркутск, Российская Федерация

Л. С. Кузина

Байкальский государственный университет, г. Иркутск, Российская Федерация

\title{
СЛУЖБА СОЦИАЛЬНЫХ НЯНЬ КАК ИННОВАЦИОННАЯ ТЕХНОЛОГИЯ СОЦИАЛЬНОЙ РАБОТЫ
}

АНнотАция. В последнее время в Иркутской области обострились социальные проблемы, связанные с семьей. Ощущается нехватка учреждений, которые бы занимались вопросами семей, проводили профилактику и организовывали поддержку, поэтому в статье рассмотрена возможность реализации инновационной технологии социальной работы в рамках социального учреждения. Представлены результаты экспертного опроса, позволившего понять, действительно ли возникла необходимость со стороны населения в открытии службы социальных нянь. Необходимость отделения, которое будет предоставлять кратковременный присмотр за детьми в Иркутске, была подтверждена экспертным опросом.

кЛючЕВЫЕ слОВА. Инновационная технология социальной работы; социальное учреждение; социальные проблемы; семья; трудная жизненная ситуация; социальный проект; Комплексный центр социального обслуживания населения; экспертный опрос; ресурсы проекта.

ИНФОРМАЦИЯ О СТАТЬЕ. Дата поступления 27 мая 2016 г.; дата принятия к печати 16 июня 2016 г.; дата онлайн-размещения 29 июля 2016 г.

O. G. Sedykh

Baikal State University, Irkutsk, Russian Federation

L. S. Kuzina

Baikal State University,

Irkutsk, Russian Federation

\section{SER VICE OF SOCIAL NURSES \\ AS AN INNOVATIVE TECHNOLOGY OF SOCIAL WORK}

\begin{abstract}
Recently, Irkutsk Oblast has seen aggravation of social problems connected with the family. There is a feeling of shortage of organizations which would deal with issues of families, carry out prevention and provide support, so the article considers an opportunity of implementing a technology of social work within the sphere of a social institution. It presents the results of an expert poll which allows to understand if there is a need on part of the population for starting the social nurses service. The necessity of a department that will provide a short-time child minding in Irkutsk is confirmed by the expert poll.

KEYWORDS. Innovative technology of social work; social institution; social problems; family; difficult life situation; social project; Complex Center for Social Public Service; expert poll; project resources.

ARTICLE INFO. Received May 27, 2016; accepted June 16, 2016; available online July $29,2016$.
\end{abstract}

Любые социальные изменения, связанные с повышением и улучшением благосостояния граждан, являются инновационными процессами, которые происходят под воздействием целенаправленных мер по созданию новых социальных институтов. Акцент на социальной направленности в государственной полити-

(С) О.Г. Седых, Л. С. Кузина, 2016

\section{Baikal Research Journal}


ке многих стран объясняется необходимостью в совершенствовании социальной работы, создании эффективной рабочей системы социальной защиты населения в стране.

Современный институт социальной работы по аналогии с технической сферой становится областью социальной инженерии, которая выполняет в обществе социально-инновационную работу по совершенствованию механизмов решения социальных проблем. Однако в современной России социальная сфера не располагает в полной мере необходимым комплексом инновационных ресурсов. В большинстве регионов используются технологические инструменты решения социальных проблем, не в полной мере учитывающие потребности разных групп населения [1, с. 126-128].

В связи с этим фактором одним из приоритетных направлений в преобразовании социальной сферы становится внедрение в практику социальной работы в социальных учреждениях и службах инновационных путей развития, связанных с разработкой новых, более эффективных, социальных услуг для населения [2, с. 98; 3, с. 115-117]. Инновационные функции социального работника предполагают творческий подход к социальной деятельности, включая обобщение практического опыта, освоение новых технологических и методических приемов, анализ слабых и сильных сторон деятельности социального учреждения.

Вся деятельность ОГАУСО «Комплексный центр социального обслуживания населения» (далее - Комплексный центр) максимально направлена на то, чтобы удовлетворять социальные проблемы Иркутского района и сглаживать социальное неравенство. Поэтому в отделении постоянно открываются новые услуги и расширяются уже функционирующие отделения.

В последнее время в Иркутской области обострились социальные проблемы, связанные с семьей. Ощущается нехватка учреждений, которые бы занимались вопросами семей, проводили профилактику и организовывали поддержку [4; 5 , с. 82]. В Приказе Министерства социального развития опеки и попечительства «Об утверждении Порядка предоставления социальных услуг в форме социального обслуживания на дому» от 11 декабря 2014 г., утвержденного в соответствии со ст. 27 Федерального закона «Об обновах социального обслуживания граждан в Российской

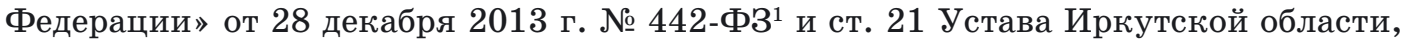
гарантируется обеспечение кратковременного присмотра за детьми.

В связи с обращениями семей г. Иркутска в Комплексный центр возникла идея о создании нового объединения «Отделение социальных нянь».

В современном мире дети являются большой ответственностью для родителей и требуют постоянного присмотра и контроля, особенно, если это дети из тех семей, которые попали в тяжелую жизненную ситуацию. Родители, помимо работы и домашних дел, обязаны сделать множество вещей для своих детей: вовремя забрать из сада или школы, покормить, помочь выполнить домашнее задание, погулять, развлечь и т. д.

Однако что делать родителям, которые столкнулись с трудной жизненной ситуацией или у них возникли неотложные дела? В современном мире очень много неполных и неолокальных (супруги живут отдельно от родителей) семей, когда нет ни единой возможности найти ребенку присмотр даже на маленький период. Родители в малоимущих семьях не всегда могут устроиться на работу и обеспечить дополнительный заработок, потому что не с кем оставить детей. Родители в многодетных семьях настоящие герои. Помимо того, что они обеспечивают своих детей всем необ-

${ }^{1}$ Об основах социального обслуживания граждан в Российской Федерации : федер. закон от 28 дек. 2013 г. № 442-ФЗ // СПС «КонсультантПлюс».

\section{Baikal Research Journal}

электронный научный журнал Байкальского государственного университета 
ходимым, они еще успевают с каждым позаниматься и обо всех позаботиться, дать необходимое воспитание и образование. А что если семья не только многодетная, но еще и малоимущая или неполная и малоимущая? Тогда трудностей в воспитании становится еще больше. Всем родителям, независимо он их статуса и заработка, иногда необходимы отдых и помощь в воспитании детей.

Именно для таких семей и появится услуга «социальная няня». Комплексный центр предоставит социального работника, который не только позаботится об обычном распорядке дня ребенка, но и позанимается с ним, обеспечит досуг, позаботится о комфорте ребенка, его самочувствии и здоровье. В это время остальные члены семьи смогут заняться своими делами дома или на работе, взять передышку и не волноваться о том, куда пристроить детей, кто бы за ними присмотрел. В дополнение такие специалисты будут иметь знания, умения и навыки, которые позволят им при воспитании детей обнаружить (если они имеются) какие-либо психологические проблемы и проблемы в психологическом или физическом развитии [6; 7, с. 372; 8, с. 72]. Если вовремя заметить у детей такие отклонения от нормы, то можно их подкорректировать без особых трудностей. Такие меры будут являться одновременно и профилактикой социальных проблем семьи и ребенка.

Следует отметить, что в Комплексный центр уже давно поступают просьбы и пожелания о предоставлении данной услуги. В такой услуге нуждаются как обеспеченные семьи, так и семьи, находящиеся в трудной жизненной ситуации. Следовательно, потенциальные клиенты обеспечат спрос, а низкая цена за услугу сможет конкурировать на рынке. Ведь услуги профессиональной няни, а не «человека с улицы» имеют очень высокую цену для среднестатистической семьи.

По данным Федеральной службы государственной статистики, в Иркутской области за последние три года возросла доля населения с денежными доходами ниже величины прожиточного минимума. От общей численности населения их доля составляла в 2013 г. - 17,0 \% , в 2014 г. - 18,6 \% , в 2015 г. - 18,9 \%. Численность детей Иркутской области от 3 до 14 лет за последние пять лет также увеличивается $[9$, с. $176 ; 10$, с. $172 ; 11$, с. 129$]$. Следовательно, малоимущих семей с детьми, которые нуждаются в дополнительных мерах социальной поддержки, становится все больше.

Перед этапом планирования проекта (на стадии инициации проектной идеи) авторами был проведен экспертный опрос, цель которого в первую очередь гносеологическая - понять, какие трудности испытывают малоимущие семьи с детьми, а также необходима ли им такая услуга, как кратковременный присмотр за детьми. Важно было узнать у экспертов, действительно ли возникла необходимость со стороны населения в открытии нового отделения социального обслуживания (службы социальных нянь).

В ходе исследования были выработаны следующие гипотезы:

1. Кратковременный присмотр за детьми - одна из самых необходимых услуг для малоимущих семей.

2. Открытие отделения социального обслуживания на дому сможет помочь малоимущим семьям в решении проблем и выходе из трудной жизненной ситуации.

3. У Комплексного центра достаточно опыта и ресурсов для того, чтобы открыть новое отделение социального обслуживания на дому (службу социальных нянь).

Для проведения исследования был выбран метод экспертного опроса, в ходе которого опросили четырех экспертов - все они являются работниками отделений социального обслуживания на дому Комплексного центра. Опрос проводился очным методом в виде стандартизированного интервью с экспертами.

Для проведения интервьюирования был составлен бланк вопросов для экспертов, отвечающий программе исследования: выдвинутым гипотезам, задачам и целям.

\section{Baikal Research Journal}


В бланк вошли небольшое количество вопросов, как открытых, так и закрытых. Составленные вопросы имели своей целью узнать мнение экспертов о проблемах малоимущих семей. Например, был вопрос о том, какие из гарантированных государством услуг наиболее необходимы малоимущим нуждающимся семьям с детьми, также была поставлена следующая цель: узнать, были ли случаи обращения семей в Комплексный центр с просьбой предоставить им услугу по кратковременному присмотру за детьми; необходимо ли отделение, которое будет предоставлять кратковременный присмотр за детьми в Иркутске; почему данная услуга все еще не предоставляется учреждениями социального обслуживания в Иркутской области; поможет ли открытие нового отделения, предоставляющего кратковременного присмотр за детьми, выйти семьям из трудной жизненной ситуации; достаточно ли ресурсов и опыта у Комплексного центра для открытия отделения социального обслуживания на дому (службы социальных нянь). Данные вопросы должны были показать сложившуюся с малоимущими семьями ситуацию и доказать необходимость в новом отделении.

С помощью экспертного опроса за два дня было проведено исследование необходимости открытия нового отделения социального обслуживания на дому (службы социальных нянь) в рамках учреждения ОГАУСО «Комплексный центр социального обслуживания населения». Четыре эксперта (специалисты отделений социального обслуживания на дому) выразили свое мнение по актуальности проблемы малоимущих семей с детьми и оценили необходимость в открытии нового отделения в рамках учреждения.

В первом вопросе экспертом предлагалось выбрать из гарантированных государством услуг те, которые наиболее необходимы малоимущим семьям с детьми. Все эксперты указали на необходимость в оказании таким семьям социально-педагогических услуг. За социально-психологические услуги проголосовали трое экспертов, за социально-бытовые - двое, за социально-правовые - двое и один эксперт указал на необходимость социально-трудовых услуг. По степени необходимости у двух экспертов на первом месте стояли социально-бытовые услуги и у двух - социально-психологические.

Свой выбор эксперты объяснили по-разному. Одни решили, что социально-бытовые услуги важнее, потому что они наиболее эффективны для нормализации морального климата семьи в решении экономических проблем и проблем с трудоустройством. Другие выделили социально-психологические, потому что моральная поддержка необходима семьям с детьми и это важно для их комфортного психологического климата. Были выделены также социально-правовые услуги, потому что семьи обычно не знают о своих правах и у них обычно не хватает времени для решения таких вопросов.

На вопрос о том, были ли случаи обращения семей в Комплексный центр с просьбой предоставить им услугу по кратковременному присмотру за детьми, лишь один эксперт ответил отрицательно, все остальные - положительно.

Необходимость отделения, которое будет предоставлять кратковременный присмотр за детьми в Иркутске, выразили три эксперта. Они объяснили этот тем, что в связи с демографической ситуацией услуга может быть востребована; в государственное учреждение обратиться за помощью с присмотром за детьми надежнее и дешевле, чем в частную организацию; спрос рождает предложение, тем более, что данная услуга гарантирована новым Федеральным законом «Об основах социального обслуживания граждан в Российской Федерации» от 28 декабря 2013 г. № 442. Один эксперт не признал данную необходимость и пояснил это тем, что в многодетных семьях, как правило, старшие дети осуществляют присмотр за младшими, т. е. спроса со стороны таких семей не будет.

\section{Baikal Research Journal}


На вопрос о причинах, почему данная услуга все еще не предоставляется учреждениями социального обслуживания в Иркутской области, два эксперта сослались на нехватку бюджетных средств и материальных ресурсов, также было выражено недовольство тем, что в данном вопросе недостаточно проработан стандарт социальных услуг и новый закон о социальном обслуживании. Один эксперт выразил предположение, что еще недостаточно много заявок и спроса на данную услугу в регионе.

Поможет ли открытие нового отделения, предоставляющего кратковременный присмотр за детьми, выйти семьям из трудной жизненной ситуации, эксперты точно не смогли сказать. Однако все эксперты выразили предположение, что данная услуга освободит родителей от части забот, что позволит им заняться решением других, более насущных проблем, что в свою очередь тоже влияет на состояние семьи и ее благополучие.

Ответы на вопрос, достаточно ли ресурсов и опыта у Комплексного центра для открытия отделения социального обслуживания на дому (службы социальных нянь), были ожидаемыми. Лишь один эксперт усомнился в том, что центр имеет достаточную материальную базу и опыт работы. Остальные трое были настроены оптимистично и ответили положительно.

После проведенного анализа результатов необходимо было сделать выводы и составить рекомендации по изучаемой теме. С помощью экспертного опроса, проведенного в Комплексном центре, мы выяснили, что малоимущие семьи с детьми наиболее нуждаются в социально-педагогических, социально-психологических, социально-бытовых и социально-правовых услугах. Приоритетными являются социально-педагогические и социально-бытовые услуги.

Из этого следует, что первая выдвинутая гипотеза верна. Кратковременный присмотр за детьми - одна из самых необходимых услуг для малоимущих семей.

Необходимость отделения, которое будет предоставлять кратковременный присмотр за детьми в г. Иркутске, была подтверждена экспертным опросом. В последнее десятилетие произошел сильный демографический рост, многодетных семей стало больше. Однако экономическая ситуация в стране ухудшилась, что пошатнуло благополучное положение некоторых семей. Государственным учреждениям социального обслуживания давно пора предоставлять услугу по кратковременному присмотру за детьми. Спрос рождает предложение, а в государственное отделение за подобной услугой обращаться намного надежнее и дешевле, чем в частные организации.

Странно, что такие услуги все еще не предоставляются в Иркутской области и соседних регионах, тем более, что данная услуга гарантирована новым Федеральным законом «Об основах социального обслуживания граждан в Российской Федерации» от 28 декабря 2013 г. № 442. Экспертный опрос объяснил это тем, что в региональных бюджетах недостаточно бюджетных средств. Именно поэтому данную услугу предоставляют только в центральных регионах страны - ведь там региональные бюджеты богаче и уровень жизни выше. В Иркутской области и соседних регионах затруднительно найти материальные и финансовые ресурсы для реализации данной услуги.

Не было доказано то, что с помощью данной услуги малоимущие семьи с детьми смогут выйти из трудной жизненной ситуации, решат частично свои проблемы. Однако экспертами отмечено то, что это значительно облегчит жизнь родителям и позволит им заняться решением педагогических, медицинских, экономических, психологических и бытовых проблем.

Из этого можно сделать вывод, что вторая выдвинутая гипотеза верна, и открытие отделения социального обслуживания на дому сможет помочь малоимущим семьям в решении проблем и выходе из трудной жизненной ситуации.

\section{Baikal Research Journal}

электронный научный журнал Байкальского государственного университета 
Комплексный центр в Иркутске - один из тех учреждений, которые имеют достаточную материальную базу и опыт работы для открытия нового отделения социального обслуживания на дому (службу социальных нянь). В учреждении уже функционируют отделения социального обслуживания на дому для престарелых и инвалидов. Эти отделения являются тем практическим опытом, который необходим для нового отделения, также показали и результаты экспертного опроса. Лишь один эксперт не увидел у учреждения необходимых материальных ресурсов и опыта для подобной работы.

Следовательно, третья выдвинутая гипотеза верна, и у комплексного центра социального обслуживания достаточно опыта и ресурсов для того, чтобы открыть новое отделение социального обслуживания на дому (службу социальных нянь).

Исходя из всего этого, Комплексный центр может открыть новое отделение социального обслуживания на дому (службу социальных нянь). Демографическая и экономическая ситуация в последние годы сильно поменялась и требует ответных изменений со стороны социальной сферы. В г. Иркутске есть спрос на данную услугу, а учреждение имеет для этого ресурсы и опыт. Не маловажно также то, что данная услуга сможет помочь малоимущим семьям в решении проблем и выходе из трудной жизненной ситуации.

Главная идея проекта «Социальная няня» состоит в том, чтобы родители имели возможность по приемлемой цене нанять хорошего и ответственного специалиста, который обеспечит необходимый присмотр для детей от 3 до 14 лет. Во время обслуживания социальный работник проследит за питанием, погуляет, обеспечит досуг, позанимается и сделает домашнее задание с ребенком, встретит со школы или заберет из детского сада. Особенно это важно родителям, которые сталкиваются с трудностями и не могут в какой-то момент обеспечить своим детям присмотр. Платную няню не все могут себе позволить. Бабушки и дедушки есть не во всех семьях, а некоторые не в состоянии присматривать за детьми. В таких случаях поможет специально обученный человек, который придет на выручку родителям.

Цель проекта заключается в обеспечении присмотра за детьми в бесплатной форме для нуждающихся семей (малоимущих, многодетных, неполных), в которых родители по различным причинам не в состоянии позволить себе платную няню и обеспечить круглосуточное присутствие рядом с детьми, и в платной форме для семей, которые не находятся в трудной жизненной ситуации. Право на бесплатное обслуживание имеют только малоимущие [12].

Для реализации социально-значимого проекта представляется важным выполнить следующие действия:

- во-первых, определение необходимых ресурсов для реализации проекта (трудовых, финансовых, материальных) и поиск возможностей для их воплощения (набор персонала, помещение для работы отделения, финансирование из бюджета);

- во-вторых, оповещение потенциальных клиентов об открытии отделения и предоставлении новой услуги (реклама, оповещение в социальной защите и детских садах);

- в-третьих, обслуживание первых клиентов, доработки.

Весь проект можно разделить на контрольные события (вехи), которые являются результатом выполнения последовательных фаз. Их можно представить в виде иерархической структуры работ - это ориентированный на результат способ группировки частей проекта, который позволяет упорядочить и определить содержание проекта, а также наглядно оценить последовательность действий. Иерархическая последовательность используется для структурированного разделения проекта и выполняемых работ на более мелкие управляемые элементы.

\section{Baikal Research Journal}


В нашем случае условно можно выделить четыре фазы проекта, описывающие поэтапные виды работ по внедрению в конкретном учреждении отделения «Социальная няня" .

Первая фаза проекта заключается в определении необходимых ресурсов - нахождение источника финансирования деятельности отделения, кадрового ресурса, материально-технического оснащения. Реализация второй фазы проекта позволяет обеспечить поиск необходимых ресурсов - составление бюджета и утверждение распорядителем бюджетных средств, отведение кабинетов под деятельность отделения, оборудование кабинетов, ремонт и установка мебели и техники, проведение собеседования и принятие на работу социальных работников. Третья фаза проекта заключается в информировании будущих клиентов созданного отделения - информирование специалистами клиентов в социальных учреждениях, распространение информации в детских садах, школах, детской поликлинике (листовки, рекламные стенды), размещение рекламы в средствах массовой информации, объявление по радио. Заключительная четвертая фаза проекта предполагает начало работы отделения - обслуживание первых клиентов, доработка и исправление выявленных ошибок, составление расписания нянь и, наконец, работа отделения в нормальном режиме.

Для реализации проекта необходимо учитывать, что государственные и финансовые ресурсы учреждение может получить только после утверждения финансирования для Комплексного центра со следующего отчетного года. Для этого необходимо включить новое отделение в бюджетную смету на 2017 г. Отметим, отделение и будет предоставлять свои услуги платно, однако, необходимо получить денежные средства для обслуживания нуждающихся граждан. Какие-либо изменения в финансировании, изменение в затратах денежных ресурсов в текущем году почти невозможно. Таким образом, реализацию проекта следует начать с августа 2016 г. и закончить январем 2017 г., когда новое отделение начнет функционировать и оказывать услуги населению.

Родители получат возможность оставить своего ребенка под присмотром. Воспользоваться услугой смогут родители, которым нужно отлучиться на пару часов, а оставить с кем-то ребенка нет возможности. В таком случае маме или папе нужно прийти в социальное учреждение, которое предоставляет данную услугу, и заключить договор. С ребенком будет находиться социальный работник. Он выполнит все необходимые функции и дополнительные по пожеланиям родителей. Некоторые смогут воспользоваться «социальной няней» бесплатно, для этого необходимо будет доказать свою нуждаемость и трудную жизненную ситуацию определенным перечнем документов. Остальным придется заплатить определенную сумму за данную услугу.

Социальные работники не смогут помочь только тем родителям, которые воспитывают детей с каким-либо тяжелым заболеванием, потому что в таком случае нужны квалифицированные специалисты с медицинским образованием.

Для реализации такого вида деятельности проекту потребуются разного рода материальные, административные, кадровые и иные ресурсы. Из материальных ресурсов понадобятся: помещение (кабинет), мебель, оборудование и техника. Все эти ресурсы Комплексный центр имеет в наличии и сможет их предоставить, если чего-то будет не хватать, то учреждение приобретет недостающее.

Финансирование проекта будет осуществляться за счет государственного бюджета. Учреждение составит смету и предоставит ее в декабре текущего года, Министерство социального развития, опеки и попечительства Иркутской области утвердит ее в январе следующего года. Данная новая услуга будет рассматриваться как государственный заказ.

\section{Baikal Research Journal}

электронный научный журнал Байкальского государственного университета 
Учреждению для открытия нового отделения будет необходима поддержка со стороны указанного министерства, так и руководителя Комплексного центра. Для обмена опытом и поддержки пригодится налаженное сотрудничество с ОГБУСО «Реабилитационный центр для детей и подростков с ограниченными возможностями" и МАУ «Консультативный центр “Дом семьи”». В этих учреждениях в дальнейшем могут быть открыты подобные отделения. Для обеспечения кадровыми ресурсами для отделения будет полезно сотрудничество с высшими и средними учебными заведениями г. Иркутска.

Для функционирования отделения необходимо следующее количество кадровых ресурсов: один заведующий отделением «Социальная няня»; пятнадцать социальных работников (нянь). Заработная плата социального работника (няни) будет состоять из оклада, надбавок (северный коэффициент, стаж работы) и стимулирующей надбавки (15\% от предпринимательской деятельности). По трудовому договору они будут работать не менее $6-8$ ч в день, пять дней в неделю, суббота и воскресенье - выходные дни.

Стоимость услуги отделения «Социальная няня» будет составлять 110 р. В учреждении уже функционирует одно отделение социального обслуживания на дому, которое обслуживает пенсионеров и инвалидов, и цена 1 ч работы сиделки составляет 110 р. Для установления такой стоимости услуги экономистами были проведены расчеты. В будущем, возможно, она изменится, так как стоимость варьируется от спроса.

В центральных регионах Российской Федерации в крупных городах в последние годы все больше стало открываться отделений социальных нянь по кратковременному присмотру за детьми. В данный момент проект уже реализован в Московской, Белгородской и Ленинградской областях. Во многих городах проект открывается пока в качестве пилотного, например, в г. Ульяновске.

В большинстве городов реализуются подобного рода проекты, однако, отличия их в том, что присмотр осуществляется за детьми-инвалидами. Отделения социального обслуживания на дому для таких детей имеют свою специфику, а работники должны обладать дополнительными навыками. Такие специалисты должны проходить профессиональную подготовку в учебных заведениях.

Реализация проекта для Восточной Сибири будет в новинку. В соседних Иркутской области регионах таких проектов пока еще не воплощали. Если провести мониторинг сайтов учреждений социального обслуживания г. Красноярска и г. Улан-Удэ, то можно заметить отсутствие подобных услуг. Социальное обслуживание на дому предоставляется только комплексными центрами и только детям с ограниченными возможностями, которые не в состоянии позаботиться о себе и сами себя обслуживать не могут. Такую работу выполняют сиделки из отделений социального обслуживания на дому для граждан пожилого возраста и инвалидов.

\section{Список использованной литературы}

1. Платонова Н. М. Инновации в социальной работе : учеб. пособие / Н. М. Платонова, М. Ю. Платонов. - 2-е изд., стер. - М. : Академия, 2012. - 256 с.

2. Галаганов В. П. Организация работы органов социального обеспечения в Российской Федерации : учебник / В. П. Галаганов. - 3-е изд., испр. и доп. - М. : КноРус, 2015. - 152 c.

3. Социальное обслуживание населения: ценности, теория, практика : учеб. пособие / под ред. Л. В. Топчего. - М. : Изд-во Рос. гос. соц. ун-та, 2011. - 320 с.

4. Особенности поведенческих стратегий учащейся молодежи в области сохранения здоровья / И. С. Карпикова, У. В. Трохирова, О. Ю. Оношко, Т. Г. Журавлева // Известия Иркутской государственной экономической академии. -2015 . - Т. 25, № 2. - С. 371-378. DOI : 10.17150/1993-3541.2015.25(2).371-387.

\section{Baikal Research Journal}

электронный научный журнал Байкальского государственного университета 
5. Модернизация социальной сферы муниципальных образований Сибирского региона как основы повышения качества жизни населения / В. И. Самаруха, А. В. Самаруха, Т. В. Сорокина [и др.]. - Иркутск : Изд-во БГУЭП, 2013. - 270 с.

6. Метелева Е. Р. Определение ключевых терминов в социальной сфере / Е. Р. Метелева // Известия Иркутской государственной экономической академии. - 2016. — Т. 26, № 1 . C. 90-98. - DOI : 10.17150/1993-3541.2016.26(1).90-98.

7. Технологии социальной работы в различных сферах жизнедеятельности / под ред. П. Д. Павленка. - М. : Инфра-М, 2009. - 596 с.

8. Трохирова У. В. Профессионализм специалистов социальной работы: сущность, критерии, способы оценки : учеб. пособие / У. В. Трохирова, Е. В. Зимина. - Иркутск : Изд-во БГУЭП, 2013. - 116 с.

9. Карпикова И. С. Показатели функционирования системы социальной защиты в аспекте оценки качества жизни населения / И. С. Карпикова / Известия Иркутской государственной экономической академии. - 2011. — № 3 (77). - С. 175-178.

10. Качество жизни населения крупного сибирского города: оценка современного состояния и возможные пути его повышения (по результатам социологических исследований в городе Иркутске) / под науч. ред. Н. Н. Даниленко, И. С. Карпиковой. - Иркутск : Изд-во БГУЭП, 2014. - 236 с.

11. Теоретико-методические аспекты исследования качества жизни населения / под ред. Н. М. Токарской, Л. В. Саниной. - Иркутск : Изд-во БГУЭП, 2013. — 180 с.

12. Карпова Т. Ю. Совершенствование управление развитием муниципального образования [Электронный ресурс] : монография / Т. Ю. Карпова. - Режим доступа : http://www.rae. $\mathrm{ru} /$ monographs/93-3169.

\section{References}

1. Platonova N. M., Platonov M. Yu. Innovatsii $v$ sotsial'noi rabote [Innovations in social work] $2^{\text {nd }}$ ed., Moscow, Akademiya Publ., 2012. 256 p.

2. Galaganov V. P. Organizatsiya raboty organov sotsial'nogo obespecheniya $v$ Rossiiskoi Federatsii [Activity management of social security bodies in the Russian Federation]. $3^{\text {rd }}$ ed., Moscow, KnoRus Publ., 2015. 152 p.

3. Topchy L. V. (ed.). Sotsial'noe obsluzhivanie naseleniya: tsennosti, teoriya, praktika [Social public services: values, theory, practice]. Moscow, Russian State Social University Publ., 2011. 320 p.

4. Karpikova I. S., Trohirova U. V., Onoshko O. Yu., Zhuravleva T. G. Features of students' behavioral strategies in health preservation sphere. Izvestiya Irkutskoi gosudarstvennoi ekonomicheskoi akademii = Bulletin of Irkutsk State Economics Academy, 2015, vol. 25, no. 2, pp. 371-378. DOI: 10.17150/1993-3541.2015.25(2).371-387. (In Russian).

5. Samarukha V. I., Samarukha A. V., Sorokina. T. V. Modernizatsiya sotsial'noi sfery munitsipal'nykh obrazovaniya Sibirskogo regiona kak osnovy povysheniya kachestva zhizni naseleniya [Modernizing social sphere of the Siberian Region municipal entities as a basis of improving public living standards]. Irkutsk, Baikal State University of Economics and Law Publ., 2013. 270 p.

6. Meteleva E. R. Determining key terms of social welfare. Izvestiya Irkutskoi gosudarstvennoi ekonomicheskoi akademii = Bulletin of Irkutsk State Economics Academy, 2016, vol. 26, no. 1, pp. 90-98. DOI: 10.17150/1993-3541.2016.26(1).90-98. (In Russian).

7. Pavlenok P. D. (ed.). Tekhnologii sotsial'noi raboty $v$ razlichnykh sferakh zhiznedeyatel'nosti [Social work technologies in various living environments]. Moscow, Infra-M Publ., 2009. 596 p.

8. Trokhirova U. V., Zimina. E. V. Professionalizm spetsialistov sotsial'noi raboty: sushchnost', kriterii, sposoby otsenki [Professionalism of social work specialists: essence, criteria, assessment methods]. Irkutsk, Baikal State University of Economics and Law Publ., 2013. 116 p.

9. Karpikova I. S. Indices of social protection system functioning in terms of public living standards assessment. Izvestiya Irkutskoi gosudarstvennoi ekonomicheskoi akademii = Bulletin of Irkutsk State Economics Academy, 2011, no. 3 (77), pp. 175-178. (In Russian).

10. Danilenko N. N., Karpikova I. S. (eds). Kachestvo zhizni naseleniya krupnogo sibirskogo goroda: otsenka sovremennogo sostoyaniya i vozmozhnye puti ego povysheniya (po rezultatam sotsiologicheskikh issledovanii $v$ gorode Irkutske) [Public living standards of a major Siberian

\section{Baikal Research Journal}


city: assessment of the current state and possible ways of increasing it (according to the results of sociological research in Irkutsk)]. Irkutsk, Baikal State University of Economics and Law Publ., 2014. $236 \mathrm{p}$.

11. Tokarskaya N. M., Sanina L. V. (eds). Teoretikometodicheskie aspekty issledovaniya kachestva zhizni naseleniya [Theoretical and methodical aspects of investigating living standards of population]. Irkutsk, Baikal State University of Economics and Law Publ., 2013. 180 p.

12. Karpova T. Yu. Sovershenstvovanie upravlenie razvitiem munitsipal'nogo obrazovaniya [Improving municipal education development management]. Available at: http://www.rae.ru/ monographs/93-3169. (In Russian).

\section{Информация об авторах}

Седых Ольга Геннадьевна - кандидат экономических наук, доцент, кафедра социологии и социальной работы, Байкальский государственный университет, 664003, г. Иркутск, ул. Ленина, 11, e-mail: sedyholga@yandex.ru.

Кузина Любовь Сергеевна - студент бакалавриата по направлению «Социальная работа», Байкальский государственный университет, 664003, г. Иркутск, ул. Ленина, 11, e-mail: luba2309@ya.ru.

\section{Authors}

Olga G. Sedykh - PhD in Economics, Associate Professor, Chair of Sociology and Social Work, Baikal State University, 11 Lenin St., 664003, Irkutsk, Russian Federation; e-mail: sedyholga@yandex.ru.

Lyubov S. Kuzina - Bachelor Degree Student in Social Work, Baikal State University, 11 Lenin St., 664003, Irkutsk, Russian Federation; e-mail: luba2309@ya.ru.

\section{Библиографическое описание статьи}

Седых О. Г. Служба социальных нянь как инновационная технология социальной работы / О. Г. Седых, Л. С. Кузина // Baikal Research Journal. — 2016. — T. 7, № 4. — DOI : 10.17150/2411-6262.2016.7(4).23.

\section{Reference to article}

Sedykh O. G., Kuzina L. S. Service of social nurses as an innovative technology of social work. Baikal Research Journal, 2016, vol. 7, no. 4. DOI : 10.17150/2411-6262.2016.7(4).23. (In Russian).

\section{Baikal Research Journal}

